\title{
Relationships between children's sugar consumption at home and their food choices and consumption at school lunch
}

\begin{abstract}
Objective: To investigate the relationships between children's food and drink choices at school lunch for children who consume high or low sugar intakes at home.

Mixed Method Design: Children's food and drinks consumption at home was assessed using diet diaries over three consecutive days. Children were classified as "high" or "low" sugar consumers at home using the WHO recommendation that free sugars should be less than $10 \%$ of their daily total energy intake. A purposive sample of children was then selected and observed during school lunch, recording food selections, food left on plates and content of packed lunches.
\end{abstract}

Setting: Six primary schools in Newham and Kent, England

Participants: Parents and children aged six-seven years

Results: Seventy-one parents completed diet diaries. From the 71, 39 children were observed during school lunch. Twenty children were high sugar consumers, 19 children were low sugar consumers; 31 children had a school meal.

Eleven of the 15 children (73\%) who had school meals and who were high sugar consumers, selected a high sugar dessert rather than fruit. Only five of the $16(31 \%)$ children who had school meals and were low sugar consumers at home chose a high sugar dessert. Most of the children who had packed lunches had sweet items, despite school policies.

Conclusions: Children who consumed high sugar intakes at home tended to select foods high in sugar for school meals or had packed lunches containing high sugar foods. The implications for public health programmes include healthy eating workshops and implementing school food policies.

Key words: Children -School lunch - Dietary - Sugar 


\section{Introduction}

There is an increased focus on children's dietary habits spurred by the rise in child obesity and tooth decay ${ }^{(1)}$. The UK National Child Measurement Programme found that $33 \%$ of children aged 10-11 were obese or overweight in $2016^{(2)}$. Similarly, approximately a third (31\%) of five-year-olds and nearly half (46\%) of eight-year-olds had experienced tooth decay in their primary (baby) teeth. The frequent consumption of food and drinks containing free sugars is a common-risk factor for both child obesity and tooth decay in children ${ }^{(3 ; 4)}$. The Scientific Advisory Committee on Nutrition (SACN) reported in 2015 that high sugar intakes increase the risk of developing type 2 diabetes, weight gain and tooth decay in children ${ }^{(5)}$. Free sugars (FS) are mono and disaccharides added to food or drinks; or sugars naturally present in honey, syrups and fruit juices excluding sugars in milk ${ }^{(6)}$. The SACN recommended that FS intake in the UK should account for no more than five percent of a person's daily energy intake ${ }^{(5)}$. The World Health Organisation (WHO) guidelines also recommended restricting FS in children's diets to less than $10 \%$ of their daily total energy intake ${ }^{(7)}$. However, data from national nutrition surveys in England shows that children's consumption of FS exceed these recommendations ${ }^{(8)}$. Children aged four to 10 years and 11 to 18 years consumed an average of $15 \%$ and $16 \%$ of their energy intake on free sugars in 2012. Developing strategies to support healthy eating requires a deeper understanding of the factors that influence children's food choices.

Children spend a significant amount of their time outside of the home environment in school which means that they have access to food or drinks available outside the home environment ${ }^{(9)}$. However, few studies have explored the relationship between dietary habits at home and food choices outside the home environment. The Department for Education in England reported that one-million primary school children $(85 \%)$ have school meals across England ${ }^{(10)}$.

The two key factors that influence what children eat at school are the availability of food options in the school meals; and, what parents decide to include in children's packed lunches. A study of primary school children in England found that sugar and total carbohydrate content in children who had packed lunches were higher than those eating school meals ${ }^{(11)}$. Although studies have explored children's food choices in school lunch, no studies have looked at the relationship between children's food consumption both at home and at school. 
Several studies examining food consumption have used an ethnographic approach, which involved participant-observations of children as the main methodology ${ }^{(12 ; 13)}$. The advantage of participant observations is that it provides a visual and objective assessment of behaviour rather than beliefs or perceptions ${ }^{(14)}$. The purpose of the school meal and packed lunch observation in this study was to assess children's food selection and choices outside of the home environment at school. This study addressed the research question: Is there a relationship between children's FS consumption at home and their food choices and consumption at school lunch?

\section{Methods}

\section{Mixed methods study design}

This study used a mixed method explanatory design ${ }^{(15)}$ which involved both quantitative and qualitative research methods in two sequential phases. In phase 1, quantitative data was collected to assess children's food and drinks consumption at home using a parent report threeday food diary, including one weekend day. This data was input into INTAKE24 ${ }^{(16)}$. The INTAKE24 is an online dietary assessment method. It is specifically designed to include the portion size of foods and it is linked to the NDNS Nutrient Databank ${ }^{(17)}$. The data was analysed to determine children's sugar consumption at home and then used to select children to take part in a qualitative study, which included non-participant observation of children's school lunch. The classification of children into high and low free sugars (FS) consumers at home was based on the percentage of energy that FS comprised of their daily energy intake as compared to the recommendation that FS should be less than $10 \%^{(7)}$. Children who had low sugar intakes at home had FS intakes that were less than $10 \%$ of their energy intake, while children who had high sugar intakes at home had sugar intakes that exceeded $10 \%$ of their energy intake. Following this classification, all the children who were high or low free sugars consumers at home were selected to take part in a qualitative study, which included non-participant observation of children's school lunch.

\section{Study population}

The study population comprised children attending primary schools in Kent and Newham in England and their parents/carers. These areas were selected to study families from both low and middle socioeconomic groups in an inner city, ethnically diverse urban population living 
in the capital city of London, in the borough of Newham; and, from a suburban, less diverse population outside London, in Kent. Newham and Kent were selected to represent two contrasting areas in England. Newham is in the top 20\% of deprived areas in England; more than a quarter (28\%) of children live in low-income households. In contrast, Kent is ranked amongst the $50 \%$ least deprived areas in England with $15 \%$ of children living in poverty ${ }^{(18 ; 19)}$

\section{Sample selection: School}

State-maintained (government funded) primary schools in Kent and Newham were the setting for this study. A list of primary schools in Kent and Newham was obtained and categorised based on the number of children within the school and the percentage of children whose first language was English. Schools with large numbers and fewer non-English speaking children were prioritised to maximise the opportunities for a good response from parents. Seventy-six schools were approached using an invitation letter sent to the head teachers asking them for permission to involve their school. Six schools agreed to participate; three schools in Newham, and three schools in Kent.

\section{Sample selection: Participants}

The participants were Year 2 children aged six-seven years old attending the six primary schools and their parents who gave their positive consent for their child to participate. Sample size requirements for participant observation studies are not based on a priori calculation but on data saturation when no new themes emerge from the observations ${ }^{(20)}$. Guidance on ethnographic studies that include non-participant observations estimate that 25-50 observations are often sufficient to obtain thematic saturation ${ }^{(21)}$.

\section{Quantitative assessment of children's dietary intakes at home}

Parents/carers who attended the six schools were asked to complete a 24-hour diet diary over three days noting their child's food and drinks intake; and, to complete a demographic questionnaire. Three consecutive days were preselected to include one weekend and two weekdays. The purpose of collecting dietary information on at least one day in the weekend was to take into account variations in children's diets, including on special occasions that occur more frequently at weekends. The diet diaries had instructions for recording food and drinks with details of the amount, portion size, brand name provided to their child, and the amount of food and drink left after the meal or snack. 
The data collected in the diet diaries was entered into INTAKE24 ${ }^{(16)}$ which computes the daily intake based on nutrient groups analysed to calculate free sugar intake and total energy intake. INTAKE24 is a validated method to be used by parents of younger children to assess dietary intake $^{(16)}$.

Each child was classified based on the daily dietary intake using the WHO recommendation. Extreme (or deviant) sampling ${ }^{(22)}$ was then used to identify the children who consumed high sugar intakes (daily total energy percentage from free sugars exceeded 10\%) or low sugar intakes (daily total energy percentage from free sugars less than 10\%).

\section{Description of food availability in the schools selected}

Schools provided a range of food options including set meals, fruit, vegetables and dessert such as cakes, pudding, flavoured yogurt, ice-cream and custard. The content of school meals varied depending on the schools' fixed main course menus. Table 1 shows the main differences and similarities between the school menus and the availability of free sugars containing food (dessert) in all six schools. The study was carried out during the summer term of 2016 and the analysis was based on the summer term menus (Table 1). All participating schools in Newham and Kent offered vegetables and fruit at school meals. Fish was usually served on Fridays in schools and the majority of schools offered a vegetarian option. Vegetables were also available in all menus including sweetcorn, salad, peas and mixed vegetables.

All six schools provided healthy drinks for children (water and milk). Only one school offered only fruit or yoghurt for dessert. Other schools served different sugar-containing dessert options. In Kent, one school had three options for lunch, either school meals, packed lunch or catering option, which included sandwiches. Only milk and water were available as drinks for children who had school meals in all schools; while children with packed lunches brought either apple or orange juice.

\section{School food policies}

Two of the three schools in Newham had Healthy School status ${ }^{(23)}$ (Table 1), which meant they followed specific requirements as part of the "Healthy Schools in London" Programme. One of these requirements was having a school food policy. Two schools in Ken had food policies based on the Eatwell plate, Changeforlife and Nutritionist resource ${ }^{(24)}$. 


\section{School lunch observations}

A qualitative researcher carried out the observations in the school on the purposive sample of children who were categorised as high and low sugar consumers. This researcher was aware of whether the child was categorised as a low or high sugar consumer during the participant observations. Each child was observed individually based on their sugar classification. Detailed information about children's food choices and observation data was written up in field notebooks. The notes were then transferred into a descriptive narrative on a digital file.

The non-participant observation of school lunches used an observation checklist developed to record the observations of both school meals and packed lunches. This checklist recorded food content, the food left on plate, the interaction between children in terms of food choices and the contribution of free sugars. Photographs of the available food at school lunch and photographs of children's plates were used to taken to provide a visual record of the content of school meals or packed lunches and the content of the food left on plate.

\section{Data analysis}

Children's diet diaries were analysed using the Statistical Package for the Social Sciences statistical software package version 22.0 (SPSS Inc., Chicago, Il, USA) to calculate their daily free sugar intake and total energy intake. Conventional content analysis ${ }^{(25)}$ was used to analyse the data gathered during school lunch observations from the observation checklists, photographs and school menus. Thirty-one children who had a school meal and eight children who had a packed lunch were included in the analysis.

\section{Results}

\section{Description of study population}

One hundred and thirty-four families agreed to participate in the study and were invited to complete a three-day diet diary. Of those parents, 71 parents completed the three-day diet diaries (38 children in Newham and 33 children in Kent). Forty-three parents out of 71 (60\%) completed the demographic questionnaire. Nearly half of the mothers (46\%), and fathers (49\%) had a university degree while $40 \%$ of mothers and $28 \%$ of fathers completed further education at college.

Thirty-nine children were purposively sampled to take part in the school lunch observations. The mean age of the children was 7.2 years $(\mathrm{SD}=0.2)$. Twenty children were observed in Kent 
and 19 in Newham. Most of the parents of the 39 children who were observed had completed either further education or had a university degree (90\%).

\section{Assessment of children's macronutrients and sugar intake at home}

Thirty-nine children were selected for school lunch observations. Table 2 shows the daily mean intake of energy, carbohydrates, total sugars, fat, saturated fat, proteins and the mean free sugars intake of the 39 children. The mean energy intake for six to seven-year-old children was $1931 \mathrm{kcal} /$ day $(1789 \mathrm{kcal}$ in Newham and $2073 \mathrm{kcal}$ in Kent). Children in Kent consumed more free sugars (75 grams/day) than children in Newham (49 grams/day) (Table 2). The FS consumption and the energy percent from FS were measured for meals and snacks at home (excluding reported free sugars from lunches during weekdays). Twenty children were categorized as high sugar consumers (total energy from FS was $\geq 10 \%$ ) and 19 low sugar consumers (total energy from FS was $<10$ ). The mean daily sugar intake was 56 grams/day for high sugar consumers and 12 grams /day for children who had low sugar intakes. The total energy from free sugars was $17 \%$ for children in the high sugar group and $5 \%$ for children in the low sugar group. The analysis of diet diaries showed that the mean intake of fruits and vegetables at home in children who had low sugar intakes was higher than the intake of children who had high sugar intakes (Table 3).

\section{Description of school lunch process}

Children who had school lunches usually sat at the same table and talked to each other. The food choices of children who sat together were similar. The time taken for children to finish eating their school lunches ranged from 10 to 15 minutes. All the schools followed the same system during school lunch, whereby the class teachers stood in front of the dining area to oversee the children who selected their own food items. Children chose items from the salad bar, as well as a main dish option and a dessert. Children who had school meals usually sat at the same table; children with packed lunches also sat together. All six schools had the same size of colour plate but the amount of food allocated to children varied in each school determined by the serving staff. Two schools in Kent served small food portions compared to other schools. After the meal, some teaching assistants checked the remaining food on children's plates and encouraged the children to finish their food. 
School meals food selection and consumption by children who consumed high and low sugar intakes at home

Seventeen children (89\%) out of the 19 children in Newham had a school meal while 14 out of the 20 children (70\%) in Kent, had a school meal. Table 4 shows the school lunch dessert selections and food consumed by children in Newham and Kent. In Newham, the sugar containing desserts were mainly flavoured yogurts while in Kent the sugar-containing desserts were puddings.

Eleven of the 15 children who had high sugar intakes at home selected a dessert with a high free sugars content rather than fruit when it was available. Figure 1a shows an example of the food selected at school lunch by a child who was a high sugar consumer at home. In contrast, only five of the 16 children categorised as "low" sugar consumers at home selected a high sugar dessert at school lunch (Figure 1c). Children who had low sugar intakes at home selected mainly flavoured yoghurts as their chosen dessert at school, while children who had high sugar intakes at home tended to select sweetened desserts at school such as ice-cream, cake, custard, pudding, flapjack and chocolate mousse. The food left on the plate of children with high sugar intakes at home included fruit and vegetables. Eight children with high sugar intakes at home left fruit and vegetables on their plates (Figure 1b). Children with low sugar intakes at home selected more fruit at school lunch but like children who had high intakes at home, they also left some vegetables on their plates (Figure 1d).

\section{Packed lunch content in children who consumed high and low sugar intakes at home}

Eight children had packed lunches. The content of packed lunches was usually a sandwich, fruit and a dessert (e.g, sweets or sweet biscuits) but there were differences in the content of food between the children. Schools had guidance that recommended avoiding unhealthy options such as sweets, confectionery and crisps and encouraging a healthy alternative instead such as bread sticks or low sugar snack bars. Four of six schools had some restrictions on confectionery and sweets as a part of their packed lunch polices. Despite this, four of the five children who had sugar intakes at home had either sweets or sweet biscuits in their packed lunches, while all three children who had low sugar intakes at home had fruit in their packed lunches. Seven of eight children had small cartoons of fruit juice and only one child had a water bottle in their packed lunch. Children left fruit and sandwiches in their packed lunches. 
This study compared the school meal selection and content of packed lunches in children with high and low sugar intakes in heterogeneous school environments in Newham and Kent, England. Whilst recognising the relatively small purposive sample size, this study suggests that there could be a trend in the relationship between children's sugar consumption at home and their choices and consumption at school. More children who had high sugar intakes at home selected foods that were high in sugar at school rather than fruit while children who had low sugar intakes at home were less likely to pick foods that were high in sugar at school lunch. This relationship may be influenced by children's learned food preferences. A preference for sweet taste is universally present in neonates, along with an aversion to sour or bitter tastes ${ }^{(26 ; 27 ; 28)}$. Both cross-sectional studies and longitudinal studies demonstrate a preference towards sweet taste in children ${ }^{(29 ; 30)}$. Children have an unlearned preference for sweet and salty foods and an innate dislike of sour and bitter tastes ${ }^{(31)}$. This innate preference for sugar-containing foods and drinks can further develop during childhood through repeated exposure to sweetened food ${ }^{(32)}$. Experience can also enhance taste preferences; earlier experiences of a particular food eaten at home are the major determinants for developing children's food acceptance patterns.

The findings in our study showed that children who high low sugar intakes at home consumed more fruits and vegetables than high sugar foods during school lunch. However, both children with high and low sugar intakes at home left fruit and vegetables on their plates at school lunch. Current evidence recommends that children eat at least five portions of a variety of fruit and vegetables each day ${ }^{(24)}$. Previous research has also shown the benefit of providing fruit and vegetables at school during early school years ${ }^{(33 ; 34)}$. A recent systematic review assessed the effect of school food environment policies on children's dietary habits and found that school food environment policies improved targeted dietary behaviours ${ }^{(35)}$. Our study suggests that offering children only fresh fruit and yoghurt as dessert options at school lunch could support children to reach their daily fruit and vegetable consumption recommendations, whilst also reducing their intake of free sugars ${ }^{(36)}$. To support this objective, fresh fruit dessert options in school meals and school food policy should follow the Eatwell Guide ${ }^{(24)}$ and sugar swaps ideas. Previous studies have shown that repeated exposure of vegetables at a younger age may be effective in encouraging children to eat more fruit and vegetables, especially before the onset of neophobia ${ }^{(37)}$. When the repeated exposure to vegetables strategy was used, younger children were less fussy about their food choices, enjoyed food more and reported lower satiety responsiveness ${ }^{(37)}$. However, findings from interviews and focus groups with children 
suggested that their perceptions about fruit and vegetables change over time through cognitive development ${ }^{(38)}$. The participant observation in our study showed that fruit and vegetables were available to all children. This highlights the role that catering staff could have to encourage children to consume those fruit and vegetables, to facilitate higher consumption through repeated exposure and encouragement.

The school lunch observations showed that the majority of children had a school meal. Since 2014, government funded schools in England provide every child in reception (aged 4-5), Year 1 and Year 2 with a hot lunchtime meal under the Universal Infant Free School Meals (UIFSM) policy. A recent cross-sectional study assessed the effect of the UIFSM policy in schools and found that it increased the uptake of school meals from over a third (38\%) of children in 201314 to $80 \%$ in $2015-16$, evident across most schools ${ }^{(39)}$. School meals are a communal experience creating opportunities to encourage healthy eating at lunchtime ${ }^{(40 ; 41)}$.

Our study found that the minority of children had a packed lunch. One school in Kent allowed crisps and sweet snacks such as cake or chocolate-coated biscuits and fruit juice to be brought to school in packed lunches. A study in English primary schools that compared the food and nutrient intakes of children eating school dinners and packed lunches found that the sugar content of packed lunches was higher in packed lunches than in school dinners ${ }^{(11)}$. Our findings agreed with Golley et al., (2010) that children having school meals were no longer consuming drinks other than milk or water, confectionery or savoury snacks compared to children who had packed lunch ${ }^{(42)}$. Children's eating behaviour at home, such as feeding practices, parenting style $^{(43)}$ and parental autonomy may contribute to parents' lunch packing decisions. A qualitative study of seven-eight -year-old children in Wales found that some children preferred packed lunches because they had greater control over what they ate at school lunch ${ }^{(44)}$. Parents often capitulated to their children's preference for unhealthy options in packed lunches, which could explain the high sugar content of food items in packed lunches identified in our study.

The findings from this study suggest that reducing children's high sugar choices at school also needs to take into account and aim to reduce their sugar choices and intakes in the home environment. Similarly, recent studies have considered food choices outside the home environment, when high sugar snacking is common at home ${ }^{(45 ; 46)}$. A cross-sectional study examined the association between the home availability of sugar-sweetened beverages and total 
sugar-sweetened beverage consumption and found that when sugar-sweetened beverages were available at school, adolescents' sugar-sweetened beverage consumption was higher among those with more frequent availability of sugar- sweetened beverages in the home. A systematic review investigated the association between the family environment and children's fruit and vegetable consumption ${ }^{(47)}$. Their findings highlighted the importance of targeting the family environment for the promotion of healthy eating behaviours among children and adolescents. There is a need for whole family approach interventions as well as trying to reduce high sugar options at school.

Families food choices at home strengthen children's preference for sugary foods and parents are usually in charge of limiting children's sugar consumption by controlling access to foods ${ }^{(48)}$. Therefore, there is an opportunity to change children's food preferences by supporting families with tools that encourage healthy food choices. One example is the using sugar swaps ideas such as the Change4 Life Public Health initiative in the UK (http://www.nhs.uk/Change4Life). The Change4Life programme encourages families and schools to promote healthy eating workshops that involve parents' education highlighting the need to restrict free sugars consumption at home.

Whilst it is possibly easier to monitor and regulate the nutritional content of school meals, there also needs to be clearer guidance for packed lunches to support parents to improve the quality of foods brought from home at lunchtime ${ }^{(49)}$. Schools are encouraged to promote healthy eating workshops that involve parents' education highlighting the fact of controlling free sugar consumption at home. Experiential learning healthy eating workshops for both parents and primary school children have been shown to reduce children's sugar consumption ${ }^{(50 ; 51)}$.

\section{Strength and limitations}

This was a mixed methods study, which included participant observations based on a qualitative research methodology reflecting the small purpose sample size. This inductive and explorative study generated hypotheses from the trends that were observed about the relationship between children's sugar intakes at home and at school. However, as with all qualitative research studies, one should be caution about generalizing the findings of this study to different settings. Transferability needs to be established in a given context.

Several methods were used to ensure the quality and convey rigour and trustworthiness in this study ${ }^{(52)}$ including the time spent in the field and using photographs and a checklist to verify 
the observations. One limitation of this study was only observing the lunch period on one occasion. Although the observations were carried out by a researcher who knew the child's status, the coding and analysis were carried out by multiple coders (KB, VM and CP). This is consistent with qualitative data analysis, which conveys credibility by using multiple coders to reduce biases.

\section{Conclusions}

This exploratory study suggested that children who consumed high sugar intakes at home, selected foods that were high in sugar in their school lunch meal or had packed lunches that also included high sugar items. School lunch creates opportunities to influence children's common food choices but requires change at the school organisation, policy and family levels. The findings from this study reinforce the conceptualized relationship between children's food choices in the school and home environments. This study highlighted the importance of school polices, which should contain guidance on both school meals and packed lunches. Implications for future public health programs include healthy eating workshops for families, both parents and children; and, clearer guidance that promotes healthier packed lunches. 


\section{References}

1. Craig R \& Mindell J (2015) Health Survey for England. Health and Social Care Information Centre.

2. NHS Digital (2016) National Child Measurement Programme, England 2015 to 2016 school year.www.content.digital.nhs.uk/searchcatalogue? productid $=23381 \& q=$ national + child + meas urement+programme \&sort=Relevance \&size=10\&page=1\#top (accessed 20 July 2018).

3. Moynihan P, Petersen PE (2004) Diet, nutrition and the prevention of dental diseases. Public Health Nutrition 7, 201-226.

4. Department of Health (2016) Childhood obesity: a plan for action. www.gov.uk/government/uploads/system/uploads/attachment_data/file/546588/Childhood_o besity_2016_2_acc.pdf (accessed 1 September 2018).

5. The Scientific Advisory Committee on Nutrition (2015) SACN Carbohydrates and Health Report, pp. 384 [PH England, editor]. London.

www.gov.uk/government/uploads/system/uploads/attachment_data/file/445503/SACN_Carb ohydrates_and_Health.pdf (accessed 20 July 2018).

6. World Health Organization (2015) Guideline: Sugars intake for adults and children. Geneva, Switzerland: World Health Organization.

http://apps.who.int/iris/bitstream/10665/149782/1/9789241549028_eng.pdf (accessed 20 July 2018).

7. WHO (2014) WHO opens public consultation on draft sugars guideline. http://www.who.int/mediacentre/news/notes/2014/consultation-sugar-guideline/en/. (accessed 20 July 2018).

8. Bates B, Lennox A, Prentice A et al. (2014) National Diet and Nutrition Survey: Results from Years 1-4 (combined) of the Rolling Programme (2008/2009-2011/12). Public Health England, and Food Standards Agency: London.

https://assets.publishing.service.gov.uk/government/uploads/system/uploads/attachment_data /file/594361/NDNS_Y1_to_4_UK_report_full_text_revised_February_2017.pdf. (accessed 20 July 2018).

9. Amini M, Dadkhah-Piraghaj M, Abtahi M et al. (2014) Nutritional assessment for primary school children in Tehran: an evaluation of dietary pattern with emphasis on snacks and meals consumption. International Journal of Preventive Medicine 5, 611.

10. Department of Education (2014) New data shows 1.3 million more infants eating free school meals: Gov.UK. https://www.gov.uk/government/news/new-data-shows-13-millionmore-infants-eating-free-school-meals. (accessed 20 July 2018).

11. Rogers I, Ness A, Hebditch K et al. (2007) Quality of food eaten in English primary schools: school dinners vs packed lunches. European Journal of Clinical Nutrition 61.

12. Kremer-Sadlik T, Morgenstern A, Peters C et al. (2015) Eating fruits and vegetables. An ethnographic study of American and French family dinners. Appetite 89, 84-92.

13. Lloyd-Williams F, Bristow K, Capewell S et al. (2011) Young children's food in Liverpool day-care settings: a qualitative study of pre-school nutrition policy and practice. Public Health Nutrition 14, 1858-1866.

14. Tugault-Lafleur CN, Black JL, Barr SI (2017) A Systematic Review of Methods to Assess Children's Diets in the School Context-. Advances in Nutrition 8, 63-79.

15. Creswell JW, Clark VLP (2007) Designing and conducting mixed methods research. 1st ed.Thousand Oaks, CA:Sage Publications.

16. Foster E, Delve J, Simpson E et al. (2014) Comparison study: INTAKE24 vs Interviewer led recall Final report: Citeseer. https://intake24.co.uk/assets/papers/Intake24-Comparisonreport.pdf. (accessed 20 July 2018). 
17. Foster E, Matthews J, Lloyd J et al. (2008) Children's estimates of food portion size: the development and evaluation of three portion size assessment tools for use with children. British Journal of Nutrition 99, 175-184.

18. Public Health England (2017) Health Newham Profile pp. 1-4.

https://fingertips.phe.org.uk/profile/health-profiles/area-search

results/E12000007?search_type=list-child-areas\&place_name=London. (accessed 20 July

2018).

19. Communities Df, and Local Government (2015) The English Index of Multiple Deprivation 2015 (IMD2015): Headlines Findings of Kent, pp. 1-7.

https://www.gov.uk/government/statistics/english-indices-of-deprivation-2015. (accessed 20 July 2018).

20. Morse JM (2000) Determining sample size: Qualitative Health Research. $1^{\text {st }}$ ed. Thousand Oaks, CA : Sage Publications.

21. Moser A, Korstjens I (2018) Series: Practical guidance to qualitative research. Part 3: Sampling, data collection and analysis. European Journal of General Practice 24, 9-18.

22. Patton MQ (2005) Qualitative Research: Wiley Online Library.

23. Healthy Schools London Programme (2013) Healthy Schools in London. http://www.healthyschools.london.gov.uk/. (accessed 20 July 2018).

24. Public Health England (2016) The Eatwell Guide How does it differ to the eatwell plate and why? London SE1 8UG: gateway number.

https://assets.publishing.service.gov.uk/government/uploads/system/uploads/attachment_data /file/528201/Eatwell_guide_whats_changed_and_why.pdf. (accessed 20 July 2018).

25. Hsieh H-F, Shannon SE (2005) Three approaches to qualitative content analysis. Qualitative Health Research 15, 1277-1288.

26. Desor J, Maller O, Andrews K (1975) Ingestive responses of human newborns to salty, sour, and bitter stimuli. Journal of Comparative and Physiological Psychology 89, 966.

27. Scaglioni S, Arrizza C, Vecchi F et al. (2011) Determinants of children's eating behavior. The American Journal of Clinical Nutrition 94, 2006S-2011S.

28. Wardle J, Guthrie C, Sanderson S et al. (2001) Food and activity preferences in children of lean and obese parents. International Journal of Obesity 25, 971.

29. Mennella JA, Pepino MY, Reed DR (2005) Genetic and environmental determinants of bitter perception and sweet preferences. Pediatrics 115, e216-e222.

30. Desor J, Beauchamp GK (1987) Longitudinal changes in sweet preferences in humans. Physiology \& Behavior 39, 639-641.

31. Birch LL, Fisher JO (1998) Development of eating behaviors among children and adolescents. Pediatrics 101, 539-549.

32. Ventura AK, Mennella JA (2011) Innate and learned preferences for sweet taste during childhood. Current Opinion in Clinical Nutrition \& Metabolic Care 14, 379-384.

33. Anderson A, Porteous L, Foster E et al. (2005) The impact of a school-based nutrition education intervention on dietary intake and cognitive and attitudinal variables relating to fruits and vegetables. Public Health Nutrition 8, 650-656.

34. Moore L, Tapper K (2008) The impact of school fruit tuck shops and school food policies on children's fruit consumption: a cluster randomised trial of schools in deprived areas. Journal of Epidemiology \& Community Health 62, 926-931.

35. Micha R, Karageorgou D, Bakogianni I et al. (2018) Effectiveness of school food environment policies on children's dietary behaviors: A systematic review and meta-analysis. PloS one 13, e0194555. 
36. Knai C, Pomerleau J, Lock K et al. (2006) Getting children to eat more fruit and vegetables: a systematic review. Preventive Medicine 42, 85-95.

37. Caton SJ, Blundell P, Ahern SM et al. (2014) Learning to eat vegetables in early life: the role of timing, age and individual eating traits. PloS one $\mathbf{9}$, e97609.

38. Zeinstra GG, Koelen MA, Kok FJ et al. (2007) Cognitive development and children's perceptions of fruit and vegetables; a qualitative study. International Journal of Behavioral Nutrition and Physical Activity 4, 30.

39.Sellen P, Huda N, Gibson S et al. (2018) Evaluation of Universal Infant Free School Meals. January 2018. http://dera.ioe.ac.uk/30988/1/UIFSM-evaluation-7.pdf. (accessed 20 July 2018). 40. Independent (2017) The health cost of cutting free school lunches will be far greater than the price of them.

https://www.independent.co.uk/life-style/health-and-families/the-health-cost-of-cutting-freeschool-lunches-will-be-far-greater-than-the-price-of-them-a7756881.html (accessed 9th July 2018)

41. Evans, C., Mandl, V., Christian, M., \& Cade, J. (2016). Impact of school lunch type on nutritional quality of English children's diets. Public Health Nutrition 19, 36-45.

42.Golley R, Pearce J, Nelson M (2011) Children's lunchtime food choices following the introduction of food-based standards for school meals: observations from six primary schools in Sheffield. Public Health Nutrition 14, 271-278.

43. Ventura AK, Birch LL (2008) Does parenting affect children's eating and weight status? International Journal of Behavioral Nutrition and Physical Activity 5, 15.

44. Warren E, Parry O, Lynch R et al. (2008) 'If I don't like it then I can choose what I want': Welsh school children's accounts of preference for and control over food choice. Health Promotion International 23, 144-151.

45. Cho D, Kim S (2018) Interplay Between Self-Efficacy and Perceived Availability at Home and in the School Neighborhood on Adolescents' Fruit and Vegetable Intake and EnergyDense, Low-Nutrient Food and Sugary Drink Consumption. Journal of Nutrition Education and Behavior 50, 856-867.

46. Haughton CF, Waring ME, Wang ML et al. (2018) Home Matters: Adolescents Drink More Sugar-Sweetened Beverages When Available at Home. The Journal of pediatrics.

47. Pearson N, Biddle SJ, Gorely T (2009) Family correlates of fruit and vegetable consumption in children and adolescents: a systematic review. Public Health Nutrition 12, 267283.

48. Mattila ML, Rautava P, Sillanpaa M et al. (2000) Caries in five-year-old children and associations with family-related factors. Journal of Dental Research 79, 875-881.

49. Evans CE, Cade JE (2017) A cross-sectional assessment of food-and nutrient-based standards applied to British schoolchildren's packed lunches. Public Health Nutrition 20, 565570 .

50. Dudley DA, Cotton WG, Peralta LR (2015) Teaching approaches and strategies that promote healthy eating in primary school children: a systematic review and meta-analysis. International Journal of Behavioral Nutrition and Physical Activity 12, 28.

51. Eisenmann JC, Gentile DA, Welk GJ et al. (2008) SWITCH: rationale, design, and implementation of a community, school, and family-based intervention to modify behaviors related to childhood obesity. BMC Public Health 8, 223.

52. Graneheim UH, Lundman B (2004) Qualitative content analysis in nursing research: concepts, procedures and measures to achieve trustworthiness. Nurse Education Today 24, 105-112. 


\section{Figure legends}

Figure 1. Photographs illustrating the foods selected by four different children and the food left on the plates in school meals by children who had high and low sugar intakes at home in six-seven year old children in Newham and Kent

Figure 1a: Photograph of a food selected as a school meal from a high-sugar child: strawberry flapjack

Figure 1b: Photograph of food left on the plate of a high-sugar child fruit and vegetables

Figure 1c: Photograph of a food selected as a school meal from a low sugar child: fruit, vegetables, cheese and pasta

Figure 1d: Photograph of food left on the plate of a low-sugar mainly vegetables 
Table 1: A summary of the school menus and food availability for the school meals for the six schools in Newham and Kent who participated in the study in May-July 2016.

\begin{tabular}{|c|c|c|c|}
\hline $\begin{array}{l}\text { School number } \\
\text { (area) }\end{array}$ & Set Main Meal & Desserts provided & School food policy \\
\hline School 1 (Newham) & $\begin{array}{l}\text { Three main choice options provided including ethnic } \\
\text { foods (e.g. chicken curry and sweet potato curry) } \\
\text { - Vegetables provided including mixed vegetables, peas, } \\
\text { sweetcorn and baked beans. } \\
\text { - Food served by school was Halal. }\end{array}$ & $\begin{array}{l}\text { Fruit, flavoured yoghurt, chocolate cake, } \\
\text { banana cake with custard, chocolate ice- } \\
\text { cream, cheesecake, apple pie with custard } \\
\text { and jelly. }\end{array}$ & $\begin{array}{l}\text { No food policy for both school meals and } \\
\text { packed lunches }\end{array}$ \\
\hline School 2 (Newham)* & $\begin{array}{l}\text { Two main choice options including a carbohydrate } \\
\text { side choice (e.g. rice, chips or potato) and vegetable } \\
\text { choice } \\
\text { - Asian food was available } \\
\text { - Food served by school was Halal. }\end{array}$ & Only dessert options were fruit or yoghurt. & $\begin{array}{l}\text { The policy is based on the Eatwell Plate } \\
\text { and is reviewed every } 3 \text { years (for school } \\
\text { meals and packed lunch) }\end{array}$ \\
\hline School 3 (Newham)* & $\begin{array}{l}\text { - A wide range of main meals options available } \\
\text { providing both Asian and British cuisine } \\
\text { - A vegetables bar was available } \\
\text { - Food served by school was Halal. }\end{array}$ & $\begin{array}{l}\text { Pudding, fruit flapjack, syrup sponge } \\
\text { with custard, jelly, ice-cream, apple pie } \\
\text { and chocolate muffins }\end{array}$ & $\begin{array}{l}\text { The policy is based on the Eatwell Plate } \\
\text { (for school meals and packed lunch) }\end{array}$ \\
\hline School 4 (Kent) & $\begin{array}{l}\text { Two main choice options provided including Asian and } \\
\text { British cuisine: fish was served on Friday. } \\
\text { - Selection of vegetables available }\end{array}$ & $\begin{array}{l}\text { Pudding, fruit, sticky toffee (custard), } \\
\text { chocolate tart, ice-cream, carrot cake and } \\
\text { jelly. }\end{array}$ & $\begin{array}{l}\text { The policy is based on the Nutritionist } \\
\text { resource (for school meals and packed } \\
\text { lunch) }\end{array}$ \\
\hline School 5 (Kent) & $\begin{array}{l}\text { - A variety of main meal options including pasta, a } \\
\text { designated meat-free day (Monday) and fish on } \\
\text { - Vegetables available including salad and beans }\end{array}$ & $\begin{array}{l}\text { Fruit, cake, jelly, cookies, iced finger bun } \\
\text { and mousse. }\end{array}$ & $\begin{array}{l}\text { No policy for both school meals and } \\
\text { packed lunches }\end{array}$ \\
\hline School 6 (Kent) & $\begin{array}{l}\text { - Different options available including meat (with pork } \\
\text { option) and vegetable options, Italian and British } \\
\text { cuisine. } \\
\text { - Fish was served on Friday. }\end{array}$ & $\begin{array}{l}\text { Fruit, ice-cream, fruit yoghurt, chocolate } \\
\text { mousse, Tutti Fruity cake, cheesecake and } \\
\text { raspberry cake }\end{array}$ & $\begin{array}{l}\text { The policy is based on the Eatwell Plate } \\
\text { and Change4Life (for packed lunch) }\end{array}$ \\
\hline
\end{tabular}

*Healthy Schools in London 
Table 2: The macronutrient intakes of six -seven year old children who participated in the study in Newham and Kent, England based on three-day food diaries reported by parents in May-July 2016.

\begin{tabular}{|c|c|c|c|c|c|c|}
\hline \multirow{2}{*}{$\begin{array}{l}\text { Macronutrient } \\
\text { intakes }\end{array}$} & \multicolumn{2}{|c|}{$\begin{array}{c}\text { Children in Newham } \\
(n=19)\end{array}$} & \multicolumn{2}{|c|}{$\begin{array}{c}\text { Children in Kent } \\
(n=20)\end{array}$} & \multicolumn{2}{|c|}{$\begin{array}{c}\text { All children } \\
(\mathbf{n}=39)\end{array}$} \\
\hline & Mean & (SD) & Mean & (SD) & Mean & (SD) \\
\hline Energy (kcal) & 1788 & (476) & 2073 & $(914)$ & 1931 & (717) \\
\hline Carbohydrate (g) & 232 & $(63)$ & 286 & (118) & 255 & (92) \\
\hline Fat (g) & 68 & $(29)$ & 83 & $(60)$ & 76 & (48) \\
\hline Saturated Fat (g) & 26 & $(10)$ & 34 & (23) & 30 & (18) \\
\hline Protein (g) & 73 & (26) & 75 & (28) & 74 & (27) \\
\hline Total sugars (g) & 101 & $(43)$ & 142 & (73) & 123 & (51) \\
\hline Free sugars(g) & 49 & $(31)$ & 75 & $(60)$ & 63 & $(50)$ \\
\hline
\end{tabular}

(SD)-standard deviation. 
Table 3: The mean daily fruit and vegetables intake at home (grams) of six -seven year old children who participated in the study in Newham and Kent, England based on the three day food diaries reported by parents in May-July 2016.

\begin{tabular}{|c|c|c|c|c|c|c|}
\hline \multirow{2}{*}{$\begin{array}{c}\text { Fruit and } \\
\text { vegetables intakes }\end{array}$} & \multicolumn{2}{|c|}{$\begin{array}{l}\text { Children in Newham } \\
\qquad(\mathrm{n}=19)\end{array}$} & \multicolumn{2}{|c|}{$\begin{array}{l}\text { Children in Kent } \\
\qquad(\mathrm{n}=20)\end{array}$} & \multicolumn{2}{|c|}{$\begin{array}{l}\text { All children } \\
\quad(\mathbf{n}=39)\end{array}$} \\
\hline & Mean & (SD) & Mean & (SD) & Mean & (SD) \\
\hline Fruit (g) & 150 & (101) & 94 & (47) & 120 & $(80)$ \\
\hline Vegetables (g) & 40 & (31) & 43 & (87) & 41 & (66) \\
\hline $\begin{array}{c}\text { Fruit and vegetables } \\
\text { intakes }\end{array}$ & \multicolumn{2}{|c|}{$\begin{array}{c}\text { All children who had } \\
\text { low sugar intakes at } \\
\text { home* } \\
(n=19)\end{array}$} & \multicolumn{2}{|c|}{$\begin{array}{l}\text { All children who } \\
\text { had high sugar } \\
\text { intakes at home** } \\
(\mathbf{n}=20)\end{array}$} & \multicolumn{2}{|c|}{$\begin{array}{l}\text { All children } \\
(\mathbf{n}=39)\end{array}$} \\
\hline & Mean & (SD) & Mean & (SD) & Mean & (SD) \\
\hline Fruit (g) & 123 & (93) & 118 & (58) & 120 & $(80)$ \\
\hline Vegetables (g) & 52 & (72) & 35 & (53) & 41 & $(66)$ \\
\hline
\end{tabular}

*Children had FS intakes that were less than $10 \%$ of their energy intake at home.

** Children had sugar intakes exceeding $10 \%$ of their energy intake at home. 
Table 4: The dessert selections and food consumed at lunch by six -seven year old children who had school meals in Newham and Kent, England, May-July 2016

\begin{tabular}{|l|c|c|c|c|}
\hline & \multicolumn{2}{|c|}{$\begin{array}{c}\text { Children who had high sugar } \\
\text { *intakes at home }\end{array}$} & \multicolumn{2}{|c|}{$\begin{array}{c}\text { Children who had low sugar *intakes } \\
\text { at home }\end{array}$} \\
\hline $\begin{array}{l}\text { Food selection } \\
\text { at school lunch }\end{array}$ & $\begin{array}{c}\text { Children in } \\
\text { Newham (n=8) }\end{array}$ & $\begin{array}{c}\text { Children in } \\
\text { Kent } \\
(\mathbf{n}=7)\end{array}$ & $\begin{array}{c}\text { Children in } \\
\text { Newham (n=9) }\end{array}$ & $\begin{array}{c}\text { Children in Kent } \\
\text { (n=7) }\end{array}$ \\
\hline $\begin{array}{l}\text { Number of } \\
\text { children who } \\
\text { selected desserts } \\
\text { containing free } \\
\text { sugars (\%) }\end{array}$ & $6(75)$ & $5(71)$ & $3(33)$ & $2(29)$ \\
\hline $\begin{array}{l}\text { Number of } \\
\text { children selected } \\
\text { desserts not } \\
\text { containing free } \\
\text { sugars (\%) }\end{array}$ & $2(25)$ & $2(29)$ & $6(67)$ & $5(71)$ \\
\hline $\begin{array}{l}\text { Number of } \\
\text { children who } \\
\text { selected } \\
\text { vegetables }(\%)\end{array}$ & $3(38)$ & $4(57)$ & $8(88)$ & $7(100)$ \\
\hline $\begin{array}{l}\text { Number of } \\
\text { children who left } \\
\text { vegetables on the } \\
\text { plate (\%) }\end{array}$ & $2(25)$ & $3(43)$ & $7(77)$ & $2(29)$ \\
\hline
\end{tabular}

Children had high intakes of free sugars at home that exceeded $10 \%$ of their energy intake. **Children had low free sugars intakes at home that were less than $10 \%$ of their energy intake. 